\title{
Treatment of Cheyne-Stokes Respiration in Patients with Congestive Heart Failure
}

\author{
Ivan Guerra de Araújo Freitas, Sônia Maria Guimarães Pereira Togeiro, Sérgio Tufik \\ Escola Paulista de Medicina - UNIFESP - São Paulo, SP - Brazil
}

\section{Introduction}

Cheyne-Stokes respiration is an event observed in patients with cardiopathies and brain/neurological diseases. It affects around $40 \%$ of stable cardiopaths with an ejection fraction (EF) $<45 \%{ }^{1}$. It is a sign of heart failure severity, being associated to an increase in the sympathetic stimulation, which is a known poor prognosis factor in these patients ${ }^{2}$. Although it can be observed during the state of wakefulness, its diagnosis is achieved through polysomnography and consists of:
- At least 03 consecutive cycles of an increasing-decreasing alteration in the respiratory range.

- One or both of the following:

a) Index of central apnea/ hypopnea $\geq 5$ per hour.

b) The increasing-decreasing cyclic alteration of the respiratory range lasts at least 10 consecutive minutes ${ }^{3}$ (Figure 1).

The mechanisms that lead to Cheyne-Stokes respiration (CSR) have yet to be completely clarified. It is known that these

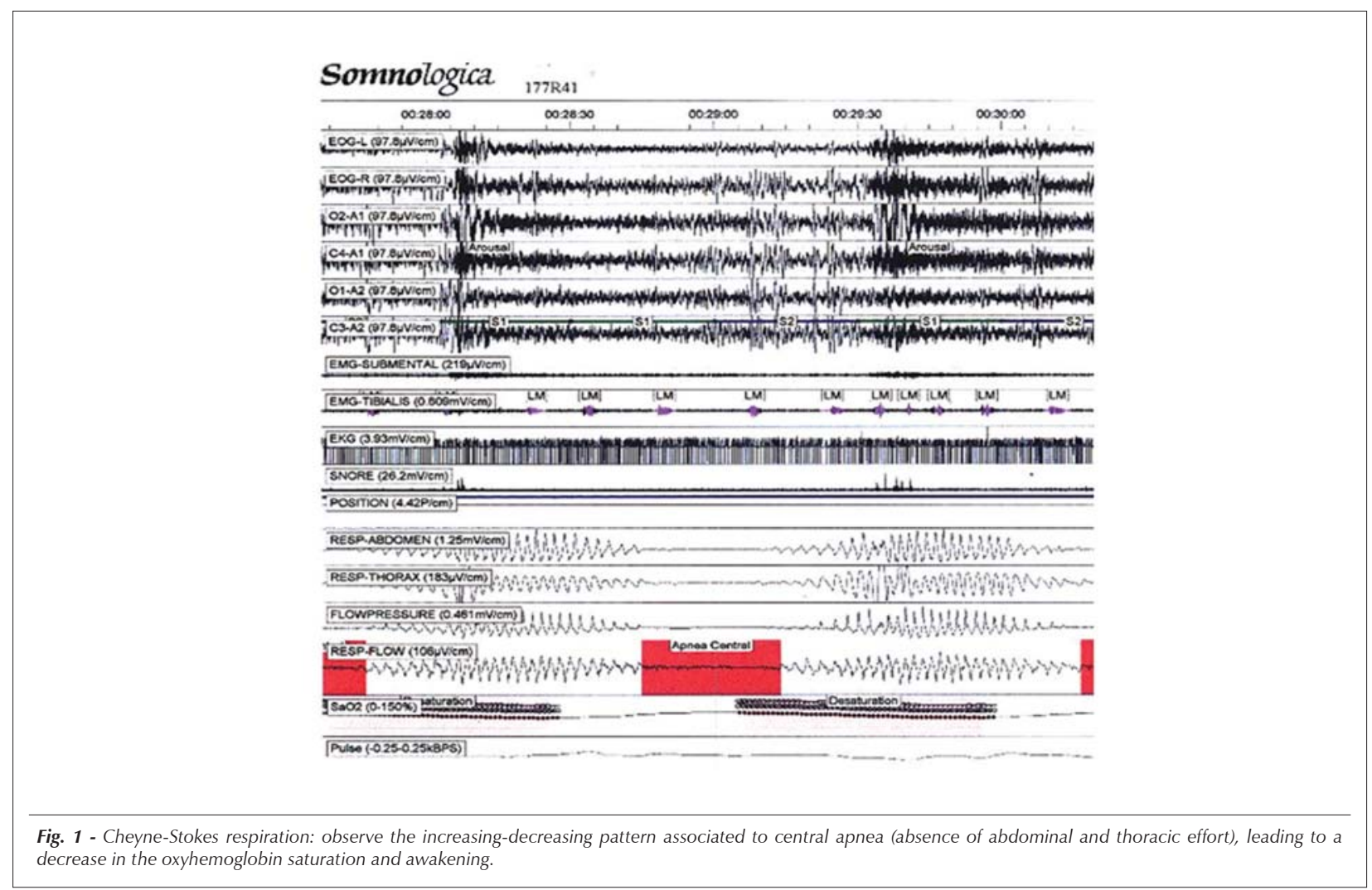

\section{Key words}

Cheyne-Stokes respiration; heart failure, congestive; hypocapnia.

Mailing address: Ivan Guerra de Araújo Freitas •

Rua Dr. Diogo de Faria, 1226/84

04037-004 - São Paulo, SP - Brazil

E-mail: drivanguerra@gmail.com

Manuscript received January 11, 2006; revised manuscript received

August 15, 2006; accepted October 9, 2006. patients are hypocapnic, which would cause the occurrence of central apnea. Several reasons for this chronic hypocapnia/ hyperventilation are speculated: a higher sensibility of the respiratory $\mathrm{CO}_{2}$ chemoreceptors; low body oxygen stores, leading to respiratory instability and hyperventilation; interstitial pulmonary edema due to high lung capillary pressure. The increase in the circulatory time of patients with congestive heart failure (CHF) is also implicated in the physiopathology of CSR, as the delayed information of the lung 
$\mathrm{Pa}_{\mathrm{CO} 2}$ variation to the respiratory chemoreceptors would cause the typical oscillation of this type of respiration ${ }^{4}$.

A research on the subject at MEDLINE showed that Continuous Positive Airway Pressure (CPAP) is the most studied modality (40\%). Oxygen therapy comprises 16\% of the References. The treatment of CSR aims at fighting hypoxia and the nocturnal awakenings present during the respiration, which increase the sympathetic activity, as well as improving diurnal somnolence and heart function. The therapeutic modalities that will be shown subsequently try to attack one of the probable mechanisms that generate the respiration (Table 1).

\section{CPAP}

The CPAP has been extensively shown as the therapeutic modality of choice in Sleep Obstructive Apnea/Hypopnea Syndrome, where it has the function of preventing the collapse of the upper airways. However, in CSR, CPAP has other functions. It increases the body oxygen stores ${ }^{5}$ through the increment of the functional residual capacity, in addition to increasing $\mathrm{PaCO}_{2}$ by decreasing the current volume. By increasing the body oxygen stores of, it reduces the respiratory instability, which is responsible for the respiration variations. The elevation of $\mathrm{PaCO}_{2}$ impairs the occurrence of central apneas due to the increase in the difference between the patient's $\mathrm{PaCO}_{2}$ and the $\mathrm{PaCO}_{2}$ of the apnea threshold. Krachman demonstrated the effects of the CPAP on body stores of $\mathrm{O}_{2}$. CPAP diminished the velocity of the oxyhemoglobin saturation decline (dSat/dt) caused by the apneas, a value that correlates negatively with the body oxygen stores ${ }^{5}$.

The positive pressure in the airways also acts by improving the ventricular function in patients with $\mathrm{CHF}$ by decreasing the pre- and post-load.

Naughton demonstrated that CPAP reduces the left ventricle (LV) end-systolic transmural pressure (LVESTMP $=$ systolic pressure of the left ventricle - esophageal pressure) and the product LVESTMP $x$ cardiac frequency (an index of systolic myocardial power generation and $\mathrm{O}_{2}$ consumption), decreasing the LV load $^{6}$. It has also been demonstrated that cardiopath patients with CSR have elevated pulmonary venous congestion and interstitial pressure ${ }^{7}$, which causes increased afferent vagal stimulation resulting in hyperventilation. CPAP also fights the interstitial edema.

Due to the fact that many of these patients snore, CPAP can also act by decreasing the airway resistance. In snorers, there is a higher decrease in the pleural pressure and therefore, a higher LV pre-load, which is corrected by making the airways more pervious with CPAP.

Several studies have shown the effects of CPAP on CSR of patients with cardiopathies, by reducing the central apnea/hypopnea index $(\mathrm{AHI})^{2,5,8-12}$, improving nocturnal oxyhemoglobin saturation $\left(\mathrm{SatO}_{2}\right)^{2,8-10,12}$, decreasing the time of CSR during sleep ${ }^{9}$ and the number of brief awakenings ${ }^{9-12}$, increasing the percentage of slow-wave sleep ${ }^{9,12}$. Its effects are also maintained during the day as observed in the LV EF improvement ${ }^{2,11,12}$, in the NYHA classification of $\mathrm{CHF}^{2,9,11,12}$, in the reduction of diurnal somnolence at the Epworth scale and decreased heart frequency during the state of wakefulness ${ }^{11}$. It also decreases the sympathetic activity by reducing the concentrations of nocturnal urinary norepinephrine and morning plasma norepinephrine ${ }^{2}$ and decreases the frequency of ventricular arrhythmias ${ }^{10}$. It increases the heart transplant free-survival and decreases the mortality/heart transplant rate as shown in a study with more than 2 years of follow$u^{13}$. As for quality of life, there was improvement in the "Chronic Heart Failure Questionnaire" score regarding the items dyspnea, fatigue, emotional well-bring, and disease domain ${ }^{11}$.

Not all patients respond to CPAP. Javaheri ${ }^{10}$ found a frequency of only $43 \%$ of responders (patients whose AHI decreased to less than 15 per hour). The non-responders had a mean $\mathrm{AHI}$ of 62 and the responders, a mean $\mathrm{AHI}$ of 36 , which shows that more severe patients may not respond to CPAP, probably due to the fact that the latter can lead to a tendency to wake up, promoting respiratory instability due to the more elevated pressures used in these patients. Other studies have found a higher frequency of responders, but they had less severe cohorts ${ }^{9}$.

Contrarily, other authors have shown that CPAP failed to improve CSR $^{14,15}$, or even showed that it can be deleterious for these patients ${ }^{15}$. A methodological error that might have contributed to the lack of success of CPAP was the protocol used in pressure adjustment, initiated arbitrarily at $7.5 \mathrm{cmH}_{2} \mathrm{O}$ or higher.

Javaheri ${ }^{10}$ and Naughton et $\mathrm{a}^{11}$ created different ways to titrate the correct pressure, but both are in agreement about starting the titration with a pressure of $5 \mathrm{cmH}_{2} \mathrm{O}$ and increasing the pressure gradually until a value that is tolerable by the patient is reached, trying to achieve between 10 to $12 \mathrm{cmH}_{2} \mathrm{O}$. Another possible explanation for the absence of beneficial effects is the CPAP evaluation after just one night of its use $^{14}$. It has been demonstrated that the benefits of CPAP are achieved with time (there is an increase in EF within 1 to 3 months of use) and the pressure level can also be optimized during treatment.

\begin{tabular}{lcccccc}
\multicolumn{5}{c}{ Table 1 - Effects on respiratory parameters and quality of sleep } \\
& Time in CSR & $\mathrm{SatO}_{2}$ & $\mathrm{AHI}$ & Short awakenings & Sleep efficiency & Slow wave sleep \\
CPAP & $\downarrow$ & $\uparrow$ & $\downarrow$ & $\downarrow$ & $\uparrow$ & $\uparrow$ \\
$\mathrm{O}_{2}$ & $\downarrow$ & $\uparrow$ & $\downarrow$ & $\downarrow$ & - & - \\
\hline Theophylline & - & $?$ & $\downarrow$ & $\downarrow$ & - \\
\hline CPAP - Continuous Positive Airway Pressure; CSR - Cheyne-Stokes respiration; AHI - apnea/hypopnea index. &
\end{tabular}




\section{Clinical Update}

Recently, an important multicentric study ${ }^{16}$ that involved 258 patients evaluated long-term use (24 months) of CPAP in cardiopaths. The result, however, was not the expected one. Although it reduced the central apnea index, increased the oxyhemoglobin saturation, improved heart function and reduced the levels of plasma norepinephrine, CPAP failed in demonstrating benefits regarding mortality and transplantfree survival.

In the beginning of the study, the transplant-free survival curve favored the control group, but 18 months later it started to favor the CPAP group, with no statistical difference at the end of the study. These results that did not corroborate the expectations generated by previous studies can be a consequence of more frequent beta-blocker use in comparison to the older ones. The concomitance of CPAP use and betablocker has limited the potential to improve the ventricular function obtained with CPAP alone.

An undesirable adverse effect of CPAP is the cardiac output decrease and consequent arterial hypotension, which can be prevented with pressure titration from $5 \mathrm{cmH}_{2} \mathrm{O}$ and its gradual elevation for days or weeks as tolerated by the patient. Another common complaint is the discomfort caused by the nasal mask.

Another method of ventilation with positive pressure (Bilevel Positive Airway Pressure, BiPAP) was compared to CPAP, but did not show any advantage when compared to the latter, in addition to its very high cost ${ }^{9}$.

\section{Oxygen}

The main effects of $\mathrm{O}_{2}$ on CSR are: increase of body oxygen stores, preventing the instability of arterial gases and the removal of the hypoxic stimulus to hyperpnea allowing the increase of $\mathrm{PaCO}_{2}$, augmenting the difference between the patient's $\mathrm{PaCO}_{2}$ and the $\mathrm{PaCO}_{2}$ of the apnea threshold ${ }^{17}$.

Studies have shown the several benefits of $\mathrm{O}_{2}$ in CSR: AHI reduction ${ }^{18-22}$, improvement of the nocturnal $\mathrm{SatO}_{2}{ }^{8,18-22}$, decrease in the mean time of $\mathrm{CSR}^{18,21}$ and brief awakenings ${ }^{18,20,22}$, increase of slow wave sleep ${ }^{18,22}$, reduction in cardiac frequency during the night ${ }^{20}$. It did not modify symptoms $\mathrm{s}^{20,21}$, but improved a cognitive function parameter: the velocity of information processing ${ }^{20}$. It reduced the sympathetic activation demonstrated by the decrease of nocturnal urinary excretion of noradrenaline ${ }^{21}$. There was an increase in peak $\mathrm{O}_{2}$ consumption at the ergometric cycle test ${ }^{20}$, which is a strong predictor of mortality; this leads to speculations about the improvement of survival com $\mathrm{O}_{2}$. Krachman et $\mathrm{al}^{8}$ compared $\mathrm{O}_{2}$ with CPAP in prospective randomized study with 25 patients and concluded that the two modalities of treatment are equally effective, although in this study CPAP as well as $\mathrm{O}_{2}$ were used for only one night. As seen before, CPAP effect depends on its long-term use.

The $\mathrm{O}_{2}$ flow used in these studies varied from 2 to $4 \mathrm{l} / \mathrm{min}$ and the response rate to $\mathrm{O}_{2}$ (percentage of those who had the $\mathrm{AHI}$ reduced to $<15$ per hour) was $39 \%{ }^{19}$. As with CPAP, the responders were those with milder CSR (lower AHI, milder oxyhemoglobin desaturation and higher $\mathrm{PaCO}_{2}$ ).

\section{Theophylline}

The mechanism through which Theophylline acts is uncertain. It is known that it inhibits phosphodiesterase, but at the concentrations used for the treatment of CSR, it does not have the inhibitory effect. At therapeutic concentrations, it competes with adenosine in some of its receptors. At the central nervous system (CNS), adenosine is a respiratory depressor and Theophylline has a respiratory stimulation effect as it competes with the first, preventing central apneas.

It has been demonstrated that Theophylline reduced $\mathrm{AHI}^{23,24}$, improved nocturnal $\mathrm{SatO}_{2}{ }^{23,24}$ and decreased total brief awakenings ${ }^{24}$ and those associated with respiratory alterations ${ }^{23}$. It did not alter sleep efficiency, sleep stages ${ }^{23,24}$, or $\mathrm{LV} \mathrm{EF}^{23}$. Additionally, it did not alter ventricular arrhythmias, suggesting that it is a safe option for these patients. It is important to know that Javaheri et $\mathrm{al}^{23}$ used $\mathrm{O}_{2}$ in patients due to oxyhemoglobin desaturation during examinations and this fact might have contributed to alterations in the results.

The Theophylline doses used were: $200-300 \mathrm{mg} /$ day $(4.3$ $\mathrm{mg} / \mathrm{kg})^{24}$ and $3.3 \mathrm{mg} / \mathrm{kg}$, twice a day ${ }^{23}$. Its defenders justify its use by mentioning the limitations of other therapeutic modalities: low adherence to CPAP and the possibility of inadvertently dislodging the $\mathrm{O}_{2}$ cannula during sleep.

\section{Other options}

1) CHF drug therapy optimization: In fact, this should be the first-choice treatment, as it is the simplest. Walsh et $\mathrm{a}^{22}$ demonstrated that patients with stable CHF with the use of furosemide alone, showed increase of slow wave sleep and REM sleep, reduction of HAI and desaturation events, as well as $\mathrm{CO}_{2}$ increment at the end of the expiration and ventilation reduction a minute after the addition of captopril $75 \mathrm{mg} /$ day for a month. Dark et $\mathrm{al}^{25}$ studied patients who were admitted due to heart failure decompensation, showing respiratory pattern abnormalities (predominantly central apnea with CSR) in all of them. After CHF compensation during hospital stay with diuretics, vasodilators, antihypertensive drugs, antiarrhythmic drugs and positive inotropics, a new polysomnography was performed with decrease in $\mathrm{AHI}$ and a tendency of $\mathrm{SatO}_{2}$ improvement.

2) Pacemaker: Left or biventricular pacemaker implant with atrial trigger mode ${ }^{26}$ showed a reduction in $\mathrm{AHI}$ and improvement in $\mathrm{SatO}_{2}$ as well as in the subjective quality of sleep, possibly due to cardiac function improvement. In this study, no patient had a conventional indication of pacemaker.

3) Benzodiazepine drugs: The reason for not using benzodiazepine drugs is the effect of increasing the awakening threshold, as it is a consequence of CSR and can be a perpetuating factor of the problem, due to hyperventilation and hypocapnia, caused by awakening. Studies have shown reduction of the brief awakenings, but no significant decrease in $\mathrm{AHI}$ or nocturnal $\mathrm{SatO}_{2}{ }^{27,28}$. Special attention should be given to the patients with obstructive apneas, as the benzodiazepine drugs can aggravate them.

4) $\mathrm{CO}_{2}$ : The use of $\mathrm{CO}_{2}(0.2-1 \mathrm{l} / \mathrm{min})$ mixed with $\mathrm{O}_{2}(2 \mathrm{l} / \mathrm{min})$ 
during sleep has been studied, and showed decrease in the duration of CSR and improvement in $\mathrm{SatO}_{2}$, but decreased the quality of sleep and increased the sympathetic activity ${ }^{29}$. Additionally, the resulting hypercapnia increases the left and right ventricular post-load. Therefore, it must not be indicated for patients with CHF.

5) Adaptive servo-ventilation (ASV): This new ventilatory modality consists of a variable ventilatory support that adapts depending on the phase of the respiration, being higher in apnea and lower in hyperventilation periods. It corrected CSR, objectively reducing the diurnal somnolence, plasma BNP levels (a marker of heart failure severity) and the excretion of urinary metadrenaline ${ }^{30}$. It improved the quality of sleep (by increasing total sleep time, sleep efficiency, percentage of REM and slow wave sleep and decreasing the brief awakening index) and reduced $\mathrm{AHI}$ and desaturations, when compared to controls. There were significant differences in some of these parameters in comparison to $\mathrm{CPAP}^{31}$.

\section{Conclusion}

Although it is the most studied treatment modality, the use of CPAP in CSR is still controversial and the experience of this treatment in Brazil is still scarce, as CPAP is not provided by the public Health Services and most patients have difficulty to buy it. $\mathrm{O}_{2}$ is an option for patients who are intolerant to CPAP or who cannot use it for any other reason. However, the long-term survival of this treatment modality has yet to be assessed. The other types of treatment reported here need further studies. CSR is a frequent event in cardiopaths and it is associated with a worse prognosis; thus, the correct diagnosis and treatment are of utmost importance.

\section{References}

1. Leung RST, Bradley TD. Sleep apnea and cardiovascular disease. Am J Respir Crit Care Med. 2001: 164: 2147-65.

2. Naughton MT, Bernard DC, Liu PP, Rutheford R, Rankin F, Bradley TD. Effects of nasal CPAP on sympathetic activity in patients with heart failure and central sleep apnea. Am J Respir Crit Care Med. 1995; 152: 473-9.

3. Sleep-related breathing disorders in adults: Recommendations for syndrome definition and measurement techniques in clinical research. The Report of an American Academy of Sleep Medicine Task Force. Sleep. 1999; 22: 667-84.

4. Kellogg RH. Central chemical regulation of respiration. In: Fenn WO, Rahn H, eds. Handbook of physiology. Baltimore, MD: Williams \& Wilkens; 1964. p. 507-34.

5. Krachman SL, Crocetti J, Berger TJ, Chatila W, Eisen HJ, D'Alonzo GE. Effects of nasal continuous positive airway pressure on oxygen stores in patients with Cheyne-Stokes respiration and congestive heart failure. Chest. 2003; 123 $59-66$

6. Naughton MT, Rahman MA, Hara K, Floras JS, Bradley TD. Effect of continuous positive airway pressure on intrathoracic and left ventricular transmural pressures in patients with congestive heart failure. Circulation. 1995; 91: 1725-31

7. Solin P, Bergin P, Richardson M, Kaye DM, Walters EH, Naughton MT. Influence of pulmonary capillary wedge pressure on central apnea in heart failure. Circulation. 1999; 99: 1574-9.

8. Krachman SL, D'Alonzo GE, Berger TJ, Eisen HJ. Comparison of oxygen therapy with nasal continuous positive airway pressure on Cheyne-Stokes respiration during sleep in congestive heart failure. Chest. 1999; 116: 1550-7.

9. Köhnlein T, Welte T, Tan LB, Elliott MW. Assisted ventilation for heart failure patients with Cheyne-Stokes respiration. Eur Respir J. 2002; 20: 934-41.

10. Javaheri S. Effects of continuous positive airway pressure on sleep apnea and ventricular irritability in patients with heart failure. Circulation. 2000; 101 : $392-7$.

11. Naughton MT, Liu PP, Bernard DC, Goldstein RS, Bradley TD. Treatment of congestive heart failure and Cheyne-Stokes respiration during sleep by continuous positive airway pressure. Am J Respir Crit Care Med. 1995; 151: 92-7.

12. Takasaki Y, Orr D, Popkin J, Rutherford R, Liu P, Bradley TD. Effect of nasal continuous positive airway pressure on sleep apnea in congestive heart failure. Am Rev Respir Dis. 1989; 140: 1578-84.

13. Sin DD, Logan AG, Fitzgerald FS, Liu PP, Bradley TD. Effects of continuous positive airway pressure on cardiovascular outcomes in heart failure patients with and without Cheyne-Stokes respiration. Circulation. 2000; 102: 61-6.
14. Buckle P, Millar T, Kryger M. The effect of short-term nasal CPAP on CheyneStokes respiration in congestive heart failure. Chest. 1992; 102: 31-5.

15. Davies RJO, Harrington KJ, Ormerod OJM, Stradling JR. Nasal continuous positive airway pressure in chronic heart failure with sleep-disordered breathing. Am Rev Respir Dis. 1993; 147: 630-4.

16. Bradley TD, Logan AG, Kimoff RJ, Series F, Morrison D, Ferguson K, et al Continuous positive airway pressure for central sleep apnea and heart failure. N Engl J Med. 2005; 353: 2025-33.

17. Berssenbrugge A, Dempsey J, Iber C, Skatrud J, Wilson P. Mechanisms of hypoxia-induced periodic breathing during sleep in humans. J Physiol. 1983; 343: 507-26

18. Hanly PJ, Millar TW, Steljes DG, Baert R, Frais MA, Kryger MH. The effect of oxygen on respiration and sleep in patients with congestive heart failure. Ann Intern Med. 1989; 111: 777-82.

19. Javaheri S, Ahmed M, Parker TJ. Effects of nasal O2 on sleep-related disordered breathing in ambulatory patients with stable heart failure. Sleep. 1999; 22: 1101-6.

20. Andreas S, Clemens C, Sandholzer H, Figulla HR, Kreuzer H . Improvement of exercise capacity with treatment of Cheyne-Stokes respiration in patients with congestive heart failure. J Am Coll Cardiol. 1996; 27: 1486-90.

21. Staniforth AD, Kinnear WJM, Starling R, Hetmanski DJ, Cowley AJ. Effect of oxygen on sleep quality, cognitive function and sympathetic activity in patients with chronic heart failure and Cheyne-Stokes respiration. Eur Heart J. 1998; 19: 922-8.

22. Walsh JT, Andrews R, Starling R, Cowley AJ, Johnston IDA, Kinnear WJ. Effects of captopril and oxygen on sleep apnoea in patients with mild to moderate congestive cardiac failure. Br Heart J. 1995; 73: 237-41.

23. Javaheri S, Parker TJ, Wexler L, Liming JD, Lindower P, Roselle GA. Effect of theophylline on sleep-disordered breathing in heart failure. N Engl J Med. 1996; 335: 562-7.

24. Hu K, Li QQ, Yang J, Hu SP, Chen XL. The effect of theophylline on sleepdisordered breathing in patients with stable chronic congestive heart failure. Chin Med J. 2003; 116: 1711-6.

25. Dark DS, Pingleton SK, Kerby GR, Crabb JE, Gollub SB, Glatter TR, et al Breathig pattern abnormalities and arterial oxygen desaturation during sleep in the congestive heart failure syndrome. Chest. 1987; 91: 833-6.

26. Sinha AM, Skobel EC, Breithardt OA, Norra C, Markus KU, Breuer C, et al. Cardiac resynchronization therapy improves central sleep apnea and Cheyne-Stokes respiration in patients with chronic heart failure. J Am Coll Cardiol. 2004: 44: 68-71. 


\section{Clinical Update}

27. Biberdorf DJ, Steens R, Millar TW, Kryger MH. Benzodiazepines in congestive heart failure: efects of temazepam on arousability and Cheyne-Stokes respiration. Sleep. 1993; 16: 529-38.

28. Guilleminault C, ClerkA, Labanowski M, Simmons J, Stoohs R. Cardiac failure and benzodiazepines. Sleep. 1993; 16: 524-8.

29. Andreas S, Weidel K, Hagenah G, Heindl S. Treatment of Cheyne-Stokes respiration with nasal oxygen and carbon dioxide. Eur Respir J. 1998; 12:
414-9.

30. Pepperell JCT, Maskell NA, Jones DR, Langford-Wiley BA, Crosthwaite N, Stradling JA, et al. A randomized controlled trial of adaptive ventilation for Cheyne-Stokes breathing in heart failure. Am J Respir Crit Care Med. 2003; 168: 1109-14.

31. Teschler H, Döhring J, Wang Y, Berthon-Jones M. Adaptive pressure support servo-ventilation: a novel treatment for Cheyne-Stokes respiration in heart failure. Am J Respir Crit Care Med. 2001; 164: 614-9. 